\title{
DESAFIO AMBIENTAL: RELATO DE UMA EXPERIÊNCIA SOBRE RESÍDUOS SÓLIDOS EM BIBLIOTECA
}

\author{
Maraína Souza Medeiros ${ }^{1}$, Pedro Henrique Pereira e Moreira ${ }^{2}$, Adilson \\ Correia Goulart $^{3}$, Éder Cairo Guimarães ${ }^{4}$, Eduardo Pereira Resende ${ }^{5}$ e \\ Rosiane Gonçalves Lima ${ }^{6}$
}

\begin{abstract}
Resumo: Os resíduos sólidos que são descartados de maneira inadequada pela população, têm interferido significativamente na qualidade ambiental. Em consequência, estudos têm sido desenvolvidos para reduzir os efeitos deletérios causados por esses materiais. Nesse viés, o objetivo deste trabalho foi promover a sensibilização ambiental nos usuários e comunidade da Biblioteca Maria Gabriela Pacheco Pardey em relação aos benefícios oriundos do reaproveitamento de resíduos sólidos descartados através de um Desafio Ambiental, integrando meio ambiente e biblioteconomia. O projeto Desafio Ambiental foi realizado na Semana Nacional do Livro e da Biblioteca do IFG - Câmpus Itumbiara e contou com a participação de 124 alunos, 12 servidores e 1 funcionária terceirizada. As atividades desenvolvidas e fundamentadas na pesquisa-ação participante foram: "Lixo por Livro"; "Caça ao tesouro: Explorando o Acervo da Biblioteca" e "Oficina de Artes". Ao final do Desafio, foram coletadas 8.631 latinhas de alumínio e 150 livros foram doados. Os resultados dessa experiência diferenciada proporcionaram uma reflexão acerca do papel educacional de uma biblioteca, da importância de ações de educação ambiental integradas ao tema resíduos sólidos e, principalmente, da troca de saberes entre os envolvidos no projeto.
\end{abstract}

Palavras-chave: Educação ambiental. Sustentabilidade. Meio ambiente. Resíduos sólidos.

\section{Introdução}

A geração de resíduos é uma consequência inevitável que resulta de qualquer atividade realizada, inclusive, pelo menor ser vivo existente no planeta. Até nas atividades mais simples que nos acompanha desde o nascimento, como, por exemplo, a respiração, produzindo dióxido de carbono, a digestão que tem como produto final as fezes e urina, produz resíduos. A geração de resíduos e seu afastamento é uma preocupação que acompanha a humanidade há milhares de anos (PEREIRA, 2019) e com o crescimento exponencial dos seres humanos no planeta, a geração e destinação final de resíduos sólidos (RS), principalmente nos centros urbanos, tornou-se um dos temas de grande relevância no que diz respeito aos problemas ambientais. Aliado a esses fatores está a industrialização, pois os produtos fabricados são, em sua maioria, não biodegradáveis e, consequentemente, são consumidos e descartados em larga escala (ATHAYDE JUNIOR; BESERRA; FAGUNDES, 2007). A problemática supracitada não é apenas pela quantidade de detritos gerados. Isso porque, além das várias toneladas produzidas diariamente, estes resíduos possuem diversificados tipos de materiais que diferem entre si pelas suas características químicas, físicas e até mesmo, biológicas (POZZETTI; CALDAS, 2019; ABU HAJAR et al., 2020).

Segundo o panorama dos resíduos sólidos no Brasil, organizado pela Associação Brasileira de Empresas de Limpeza Pública e Resíduos Especiais (ABRELPE), em 2018 foram geradas 79 milhões de toneladas de resíduos sólidos urbanos (RSU) e, deste total, apenas 72,7 milhões de toneladas foram coletadas, ou seja, 6,3 milhões de toneladas

\footnotetext{
1E-mail: maraliss@hotmail.com Brasil.

2E-mail: pedro.moreira@ifg.edu.br

${ }^{3}$ E-mail: adilson.goulart@ifg.edu.br

${ }^{4}$ E-mail: eder.guimaraes@ifg.edu.br

${ }^{5}$ E-mail: eduardo.pereira@ifg.edu.br

${ }^{6}$ E-mail: rosiane.santana@ifg.edu.br
}

Instituto Federal de Goiás, Campus Itumbiara. Avenida Furnas, n 55, Village Imperial, CEP: 75.524-245. Itumbiara - GO, 
de resíduos deixaram de ser coletadas em seus locais de geração. Fato preocupante, pois tais resíduos possivelmente foram descartados de forma incorreta, oferecendo riscos ao meio ambiente e servindo de moradia para vetores transmissores de doenças como, por exemplo, ratos, mosquitos como aedes aegypti, dentre outros (ABRELPE, 2019).

Os resíduos sólidos podem resultar de atividades industriais, domésticas, hospitalares, comerciais, agrícolas, de serviços e de varrição (BITENCOURT et al., 2013). Na tentativa de minimizar os impactos ambientais e ainda oferecer ferramentas para melhor gerenciamento dos diferentes tipos de RS gerados no Brasil, em 2010 foi sancionada a Lei 12.305 (BRASIL, 2010), a Política Nacional de Resíduos Sólidos (PNRS). O documento tem como objetivo principal regulamentar, estruturar e padronizar a forma com que os brasileiros manejam a geração e destinação final dos RS gerados nas diferentes atividades realizadas no país. A Lei em seu texto exige probidade tanto de setores públicos quanto de setores privados, no gerenciamento, na divulgação das informações acerca dos resíduos gerados, sugere boas práticas de consumo, além de demonstrar a importância e a necessidade da reciclagem e o reaproveitamento dos $\mathrm{RS}$ para reduzir a geração dos mesmos e minimizar a extração de novos recursos naturais (BRASIL, 2010).

Posteriormente à publicação da PNRS, constatou-se o avanço no melhoramento da discussão, conscientização e preocupação em relação à geração de resíduos, reciclagem e reutilização de materiais em âmbito nacional (ABRELPE, 2019). No entanto, devido à relevância deste assunto, é necessário o constante debate em todas as organizações quer seja ela pública ou privada. Devido ao seu comprometimento com as gerações futuras e seu caráter multiplicador de opinião, as instituições de ensino são locais de suma importância para se colocar em pauta a discussão acerca desta temática. Deste modo, programas e campanhas desenvolvidos em instituições de ensino cujo intuito seja incentivar e colocar em evidência a importância do consumo consciente e a real necessidade de se criar o hábito de reciclar e reutilizar são muito importantes (JULIATTO; CALVO; CARDOSO, 2011).

Em sua maioria, os RS lançados na natureza levam muito tempo para se decomporem e desaparecerem dos compartimentos ambientais. Esta poluição antrópica provoca efeitos devastadores em toda biota. Assim sendo, faz-se necessário sensibilizar cada ser humano sobre a sua responsabilidade com o Planeta, incentivando o consumo consciente e destinação final correta dos resíduos gerados (SPINELLI et al., 2016). Existem diferentes formas de conscientizar pessoas para mudança de hábitos ruins. No que tange ao meio ambiente e sustentabilidade, uma das melhores e principais ferramentas é a educação ambiental (EA) (JACOBI; GRANDISOLI, 2017; EVERTON; VIESBA; ROSALEN, 2019).

A educação ambiental progressivamente tem mostrado a sua importância, em alguns currículos escolares o assunto tem sido inserido na grade curricular como disciplina obrigatória. Entretanto, um problema que tem sido observado é que na maioria das vezes o tema tem sido trabalhado em disciplinas específicas e de forma isolada (SILVA, V. R. M. J.; SILVA, A. L. J.; CARDOSO, 2019). Para Silva et al. (2019), quando se trabalha a EA de forma contextualizada e interdisciplinar a formação de pessoas críticas e reflexivas acontece de maneira mais fácil e eficaz. Desta maneira, trabalhar a EA em forma de desafios, gincanas, jogos e outros eventos que sensibilize o indivíduo por meio de temas ambientais, além de ser prazeroso para o educando torna possível aplicar os conceitos da EA no cotidiano desse indivíduo.

Nessa perspectiva, a presente pesquisa pretende evidenciar que profissionais de biblioteconomia podem contribuir para a educação ambiental por meio da realização de atividades relacionadas aos resíduos sólidos dentro de uma biblioteca. Assim, este estudo entende que essas atividades que integram meio ambiente e biblioteconomia são capazes de influenciar na sensibilização dos participantes (alunos e servidores), haja vista que o espaço de uma biblioteca é bastante frequentado pela comunidade acadêmica. Além disso, incentiva o conhecimento dos conceitos de biblioteconomia e os benefícios da leitura por parte dos usuários.

Portanto, o objetivo deste trabalho foi promover a sensibilização ambiental nos usuários e comunidade da Biblioteca Maria Gabriela Pacheco Pardey em relação aos benefícios oriundos do reaproveitamento de resíduos sólidos descartados através de um Desafio Ambiental, integrando meio ambiente e biblioteconomia. 


\section{Metodologia}

Esta pesquisa apresenta como natureza científica a pesquisa-ação participante, na qual buscou-se estabelecer um envolvimento ativo entre os pesquisadores e o público-alvo, favorecendo, assim, a troca de saberes a respeito do problema ambiental investigado (GIL, 2002; MARCONI; LAKATOS, 2003). Ademais, o método da pesquisa-ação participante também é defendido por Medeiros et al. (2017) como instrumento facilitador da participação dos envolvidos, assim como orientador na tomada de decisões coletivas durante o processo de conscientização ambiental.

A pesquisa foi desenvolvida com alunos e servidores do IFG-Campus Itumbiara adotando-se como abordagem educativa a conteudista-racionalista. Segundo a teórica em EA, Tozoni-Reis (2008), esse tipo de abordagem leva em consideração que o processo de transmissão/assimilação tem como consequência uma relação mais adequada entre o sujeito e o meio ambiente. Além disso, existe uma orientação embasada no meio ambiente para que o processo educativo de transmissão dos conhecimentos técnicos científicos ocorra da melhor forma possível.

Inicialmente, foi realizada uma reunião com a direção geral do IFG-Campus Itumbiara para apresentação do projeto e obtenção do consentimento formal para realização deste estudo na biblioteca. Além disso, para preservar os direitos fundamentais e de personalidade dos participantes (BRASIL, 1988; BRASIL, 2002), optou-se por não apresentar os rostos destes nos resultados do Desafio Ambiental. Entretanto, todos os participantes estavam cientes e concordaram com os registros das atividades, autorizando a divulgação dos resultados do Desafio em publicações futuras (artigos científicos, capítulos de livro ou congressos).

A abordagem de assuntos relacionados à temática sustentável na educação básica e superior influencia na preservação do meio ambiente por meio da adoção de práticas corretas. Nesse sentido, Távora (2012) desenvolveu um projeto intitulado Lixo: fonte inesgotável de riqueza em uma escola pública com ações de EA envolvendo atividades como gincanas, palestras e concursos a partir da temática resíduos sólidos. Durante o período de execução do projeto, Távora (2012) percebeu uma melhora na gestão dos resíduos sólidos em Itapipoca-CE, assim como o desenvolvimento do pensamento ecológico dos alunos. Nesse viés, priorizou-se, no presente Desafio Ambiental, a execução de atividades que promovessem a sustentabilidade e, ao mesmo tempo, o estímulo à leitura. Valorizou-se o uso de materiais coletados pelos servidores ou reaproveitados de atividades e eventos ocorridos anteriormente. $\mathrm{O}$ público-alvo foi a comunidade interna e local do IFG - Câmpus Itumbiara. A proposta foi dividida em três etapas: a campanha Lixo por Livro, a Oficina de Artes e a dinâmica Caça ao Tesouro: Explorando o Acervo da Biblioteca (Figura 1).

Figura 1 - Fluxograma com a representação gráfica do Desafio Ambiental

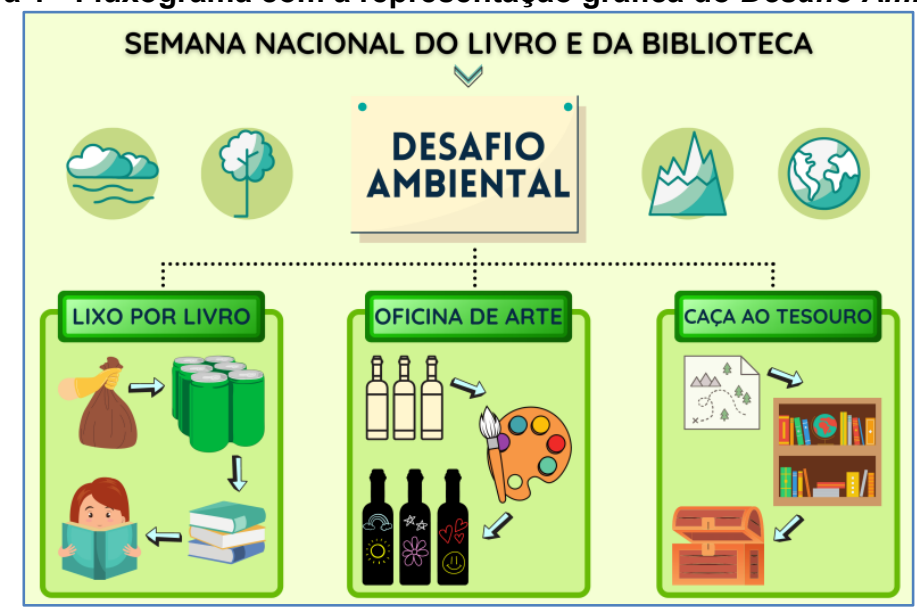

Fonte: Autores (2020)

O Desafio foi executado durante três meses (agosto a outubro de 2019), sendo a oficina e a dinâmica realizadas cada uma em único dia. A Campanha Lixo por Livro teve 
maior tempo de duração (três meses) para incentivar os alunos a adquirirem os livros doados por meio da troca de 20 latinhas por um livro, mas também de incentivar a gestão adequada desses resíduos.

\subsection{Campanha Lixo por Livro}

O campus Itumbiara conta com um sistema de coleta seletiva em todos os blocos da Instituição de Ensino, além de um serviço de limpeza terceirizado frequente ao longo do dia que permite uma boa qualidade ambiental. Nessa perspectiva, Almeida (2018) enfatiza que avaliar a gestão de resíduos sólidos comuns, orgânicos e especiais em uma Instituição de Ensino e, ao mesmo tempo, promover a sensibilização ambiental desses estudantes de forma contínua por meio de projetos, programas de conscientização e parcerias com instituições sociais é primordial para se oferecer à sociedade significativas contribuições e soluções para a problemática dos resíduos sólidos.

Para a campanha Lixo por Livro, optou-se pela coleta de latas de alumínio utilizadas no acondicionamento de bebidas, de quaisquer tamanhos, tendo em vista a facilidade de esse material ser encontrado em grandes quantidades e em diversos estabelecimentos. Ademais, a viabilização da venda desse tipo de resíduo foi levada em consideração no momento da escolha. Para o armazenamento do material coletado foram utilizados sacos de lixo resistentes, em cor preta e com capacidade para 100 litros, por facilitarem o transporte no momento da venda e auxiliarem na diminuição dos riscos de infestação. À medida que eram completados três sacos de latinhas, o setor de biblioteca entrava em contato com uma empresa de materiais recicláveis da região de ItumbiaraGO para a venda deste material.

Além disso, utilizou-se folhas de papel E.V.A, em cores diversas, para a decoração do espaço em que os livros foram expostos (estande da campanha). O mesmo material foi empregado na decoração do medidor de latinhas, onde também foram utilizados pedaços de isopor, garrafas PET coletadas pelos servidores e uma estante vazia da Biblioteca.

Para o controle das arrecadações de latinhas e livros doados durante a troca (20 latinhas por um livro à escolha do participante), elaborou-se uma planilha no Excel e uma lista física redigida no Word. A planilha tinha a finalidade de garantir 0 controle das doações pelos organizadores do projeto. Já a lista tinha a finalidade de controlar as doações de forma mais rápida e por meio da assinatura do participante (Figura 2). Nessa etapa, a primeira e a segunda equipes que coletassem mais latinhas acumulariam, respectivamente, quinze (15) e dez (10) pontos no placar final.

Para facilitar a visualização dos medidores de latinhas, as equipes foram nomeadas de $\mathrm{A}$ a $\mathrm{H}$, conforme a quantidade de cursos ofertados pela instituição de ensino: Equipe $A$ - técnico integrado em eletrotécnica; Equipe $B$ - técnico integrado em química; Equipe C - engenharia de controle e automação; Equipe D - engenharia elétrica; Equipe $E$ - licenciatura em química; Equipe $F$ - técnico subsequente em eletrotécnica; Equipe G - EJA - agroindústria; Equipe $\mathrm{H}$ - especializações (ensino de ciências e matemática, e fontes renováveis).

Figura 2 - A) Planilha de controle das doações de latinhas eletronicamente e B) Lista de doações para o controle imediato das doações

A)

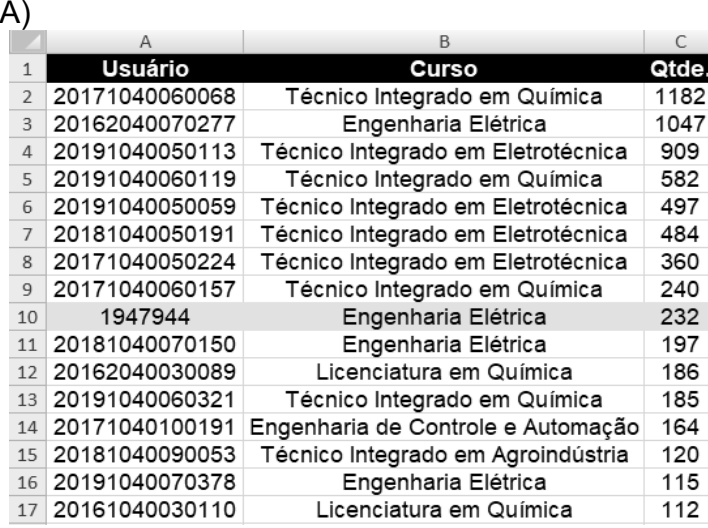

Fonte: Autores (2020)
B)

LISTA DE ARRECADAÇÃO DE LATINHAS

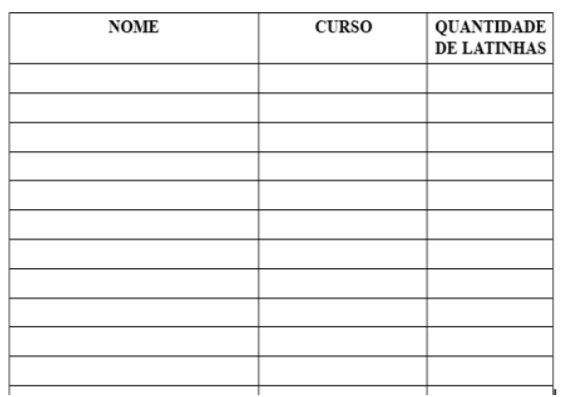




\subsection{Oficina de artes}

Como a proposta da oficina era produzir artigos de decoração por meio de resíduos descartados, optou-se por utilizar garrafas de vidro como matéria-prima, normalmente utilizadas na comercialização de bebidas alcoólicas. As garrafas foram recolhidas pelos servidores do setor, com a ajuda de outros colaboradores da instituição. Para a pintura e personalização dos itens, foram necessárias tintas acrílicas foscas, próprias para artesanato e em cores diversas, além de pincéis chatos de numerações $4,6,8$ e 10. Parte desse material foi obtido com o dinheiro arrecadado na venda das latinhas. Pesquisa semelhante foi realizada por Silva e Neves (2020), na qual tinha como objetivo a produção de espaços para acomodações na escola com o conhecimento prévio dos alunos sobre EA em uma oficina de materiais recicláveis.

De forma a manter a organização do ambiente durante a execução da oficina, foram dispostas três mesas na área de circulação da biblioteca, cobertas com folhas de jornal. Para que os pincéis estivessem sempre limpos, foram utilizadas flanelas e pequenas quantidades de água, colocadas em recipientes feitos de garrafas PET. Nessa atividade, cada aluno inscrito e presente garantiria um ponto para a equipe à qual era pertencente.

\subsection{Caça ao tesouro: explorando o acervo da biblioteca}

Como o Desafio Ambiental teve o estímulo à leitura como um de seus eixos, a dinâmica Caça ao Tesouro: Explorando o Acervo da Biblioteca foi idealizada a fim de que os alunos adquirissem interesse pela forma com que os livros são classificados e dispostos nas estantes da biblioteca. Para isso, inicialmente o bibliotecário do setor preparou uma apresentação geral envolvendo biblioteconomia, adotando como método um bate-papo descontraído com os alunos participantes e realizando tour pelo acervo da biblioteca. Problematizar a formação de leitores com o conhecimento do espaço da biblioteca, segundo Moreira e Duarte (2013), é fundamental para estimular o trabalho com a leitura por meio da ação colaborativa entre bibliotecário e professor.

Após essa explanação, seguiu-se para a atividade prática, na qual foi utilizado um criptex, em que era registrada a senha a ser desvendada pelos participantes, além de folhas de papel A4 na cor verde, que foram utilizadas no processo de impressão de mapas com as sequências de diretrizes a serem seguidas pelos participantes. Os brindes destinados aos vencedores de cada rodada alternavam-se entre livros e kits compostos por caneta e bloco de papel, excedentes de eventos anteriores. Em relação à pontuação dessa etapa, a equipe vencedora de cada uma das sete primeiras rodadas acumularia um ponto. $\mathrm{Na}$ oitava rodada, a bonificação era equivalente a dois pontos.

\section{Resultados}

Além dos alunos participarem das atividades, também houve a mobilização de servidores e terceirizados da própria instituição, mostrando assim que a proposta teve um alcance maior do que inicialmente esperado pelos autores do projeto. Alunos de escolas da comunidade externa também se encantaram com a proposta, quando visitaram a biblioteca em função do projeto Conhecendo o IFG. Este resultado, segundo Cardoso (2010), pode estar relacionado às habilidades e competências do bibliotecário como educador, uma vez que se trata de um grande disseminador da informação ambiental e da sua grande integração com o usuário da biblioteca. Melo e Pessoa (1998), por exemplo, ao desenvolverem o projeto Lixo por Livro também observaram que a ação minimizou diversos problemas de ordem social, pois favoreceu o acesso à cultura sem nenhuma restrição, contribuindo para a formação de uma sociedade mais justa.

\subsection{Campanha Lixo por Livro}

Para a atividade Lixo por Livro, os alunos do Campus foram divididos em grupos de $\mathrm{A}$ a $\mathrm{H}$ (conforme descrito na metodologia) no intuito de promover o envolvimento e a participação de todos matriculados na instituição. Para facilitar a contagem de latinhas arrecadadas por cada grupo foi construído um Medidor de latinhas e colocado no centro da biblioteca para que todos os participantes pudessem ver o andamento da arrecadação e o grupo que estava ganhando, a princípio. O estande com o nome da campanha Lixo por Livro e os livros a serem trocados pelas latinhas ficavam na entrada da 
biblioteca para atrair os olhares dos alunos para participarem da atividade (Figura 3).

Essa estratégia chamou a atenção e despertou a curiosidade dos alunos do IFG e, principalmente, alguns alunos até ficavam perto do medidor para acompanhar a evolução do seu grupo. Esse mesmo resultado foi observado por Friede et al.
(2019) que ao instalarem um Posto de Entrega Voluntária de resíduos sólidos no pátio da escola (espaço de muita movimentação de pessoas) atraiu a participação de alunos do ensino fundamental e médio, apesar destes não terem participado das aulas de Educação Ambiental (EA) aplicadas inicialmente no projeto.

Figura 3 - A) Campanha Lixo por Livro, B) Medidor de latinhas e C) Garrafa pet representando o

A)

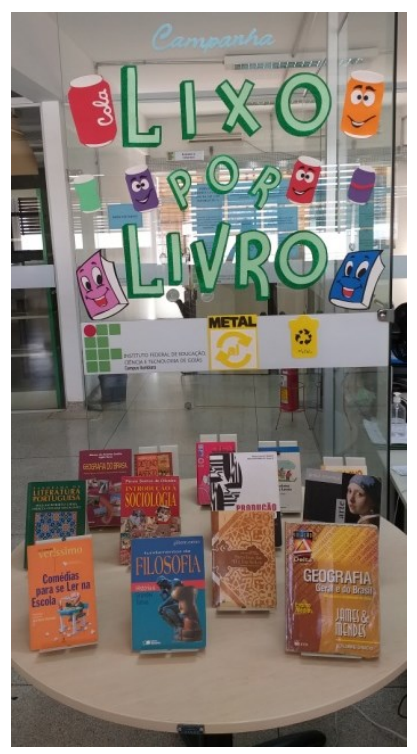

B)

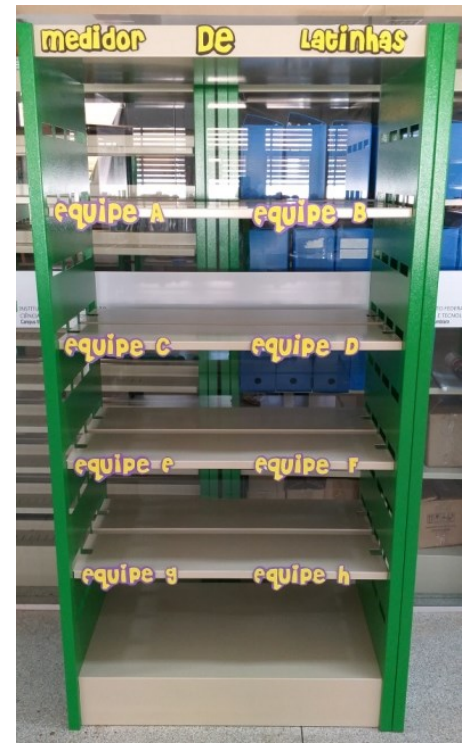

C)

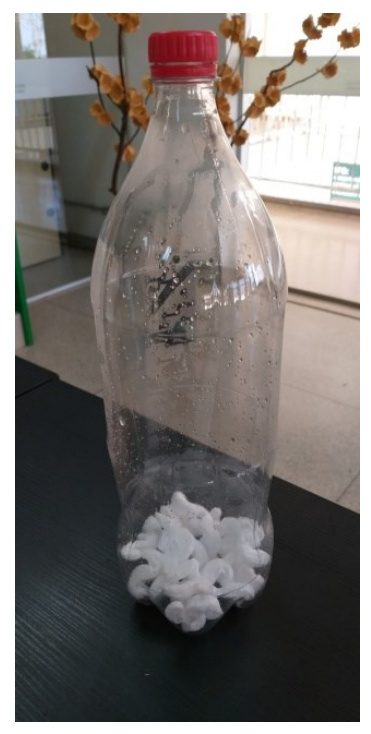

Fonte: Autores (2020)

Por se tratarem de livros de diversas classificações (técnico-científicos, literatura, didático-pedagógicos), no início da campanha Lixo por Livro houve uma procura expressiva por parte dos participantes (Figura 4), e alguns, inclusive, mencionaram que iriam dar os livros trocados para os filhos, outros para estudo próprio (concursos e vestibulares). Essa forte presença da comunidade local, assim como do corpo discente e docente, foi observada no projeto de Medeiros, Silva e Araújo (2019), os quais salientam que as atividades iniciais do projeto demonstraram a importância de atividades vinculadas à biblioteca como instrumento de integração da comunidade local com a arte da palavra, gerando o conhecimento, prazer, inspiração e instrumento de transformação social.

Figura 4 - A) Organizadora do Desafio Ambiental entregando um livro para uma das alunas participantes e B) Latinhas de alumínio doadas pelos alunos

\section{A)}

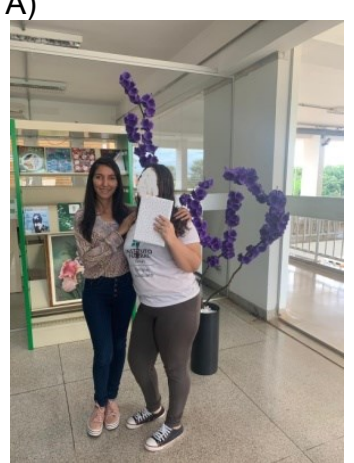

Fonte: Autores (2020)

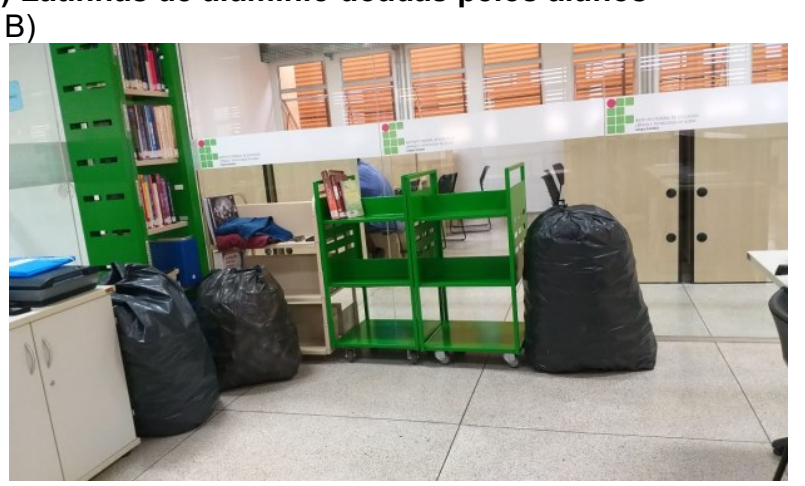


Além dos alunos terem o desafio de arrecadar as latinhas para a atividade Lixo por Livro, os servidores da biblioteca também enfrentaram adversidades como, por exemplo, encontrar garrafas PET de $2 \mathrm{~L}$ de capacidade e transparentes na cidade de Itumbiara-GO para compor o Medidor de latinhas. No entanto, este contratempo teve o seu lado positivo, isso porque, nesse momento foi solicitada ajuda dos servidores do Campus quanto à arrecadação de garrafas PET. No momento da solicitação, os mesmos eram informados quanto aos efeitos deletérios e correta destinação final deste material. Com isso, foi verificado um engajamento dos servidores na atividade. Este envolvimento pode ser mensurado pela arrecadação das garrafas PET e ainda pelo feedback no momento do recebimento delas. Segundo Fagundes et al. (2019), a criação de campanhas educativas em escolas e comunidades contribui para o manejo correto desses materiais nas cooperativas, sem contar que auxiliam na construção do pensamento ecologicamente correto de boa parte da população.

O acondicionamento das latinhas coletadas ao longo da campanha foi feito em sacos de lixo comum, de cor preta, com capacidade para cem litros, e o armazenamento foi realizado em uma sala à qual os alunos não tinham acesso. Periodicamente, as latinhas eram vendidas para uma empresa de reciclagem da cidade de Itumbiara-GO e, com a maior parte do valor arrecadado, foi contratado um serviço de cópias de chaves para os armários disponibilizados na entrada da Biblioteca (Figura 5).

Desde o início da campanha foi divulgado pelos autores do projeto que o valor arrecadado na venda das latinhas seria convertido em alguma ação em prol dos próprios usuários da biblioteca. Ao total, foram arrecadadas oito mil seiscentas e trinta e uma latinhas, havendo a mobilização de cento e quatorze alunos e doze servidores, e foram doados 150 livros. O valor arrecadado na venda das latas foi de $R \$ 250,00$. Ao contrário da presente proposta, Melo e Pessoa (1998) converteram o dinheiro arrecadado no projeto Lixo por Livro na aquisição de livros para escolas de ItabiraMG.

Figura 5 - A) Latinhas de alumínio sendo vendidas a uma empresa de materiais recicláveis e B)

A) Chaves dos guarda-volumes da Biblioteca após a realização do serviço de cópias

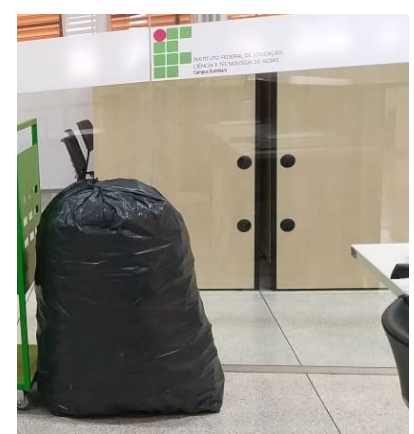

Fonte: Autores (2020)
B)

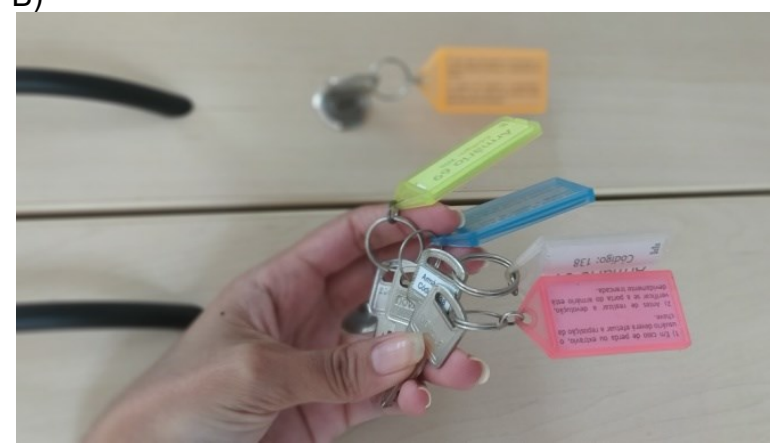

Conforme mencionado na metodologia, cada lata de alumínio entregue pelo participante garantia pontuação para a equipe/curso na qual ele está matriculado ou que ele desejava doar suas latinhas. A equipe com maior número de latinhas doadas recebeu a pontuação de 15 pontos, isto é, a equipe $B$ (Curso técnico integrado em química). A segunda colocada recebeu a pontuação de 10 pontos, isto é, a equipe $A$ (Curso técnico integrado em eletrotécnica). Observou-se pelos resultados que a participação dos alunos do ensino médio (Equipes A e B) foi mais expressiva do que os cursos de graduação e pós-graduação. Possivelmente estes resultados estejam relacionados à participação mais ativa do ensino médio em todas as atividades que são propostas pela biblioteca, assim como pela sensibilização desses alunos quanto aos efeitos negativos causados pelos resíduos sólidos ao meio ambiente. Cembranel, Francischett e Rodrigues (2019), verificaram que a aplicação de ações de EA influenciou significativamente na gestão dos resíduos sólidos na escola, pois o processo de sensibilização ocorreu de forma ininterrupta, aprimorada, ideológica, reflexiva e 
fundamentada. Nesse mesmo sentido, Sereia et al. (2013) apontam que a escola é um importante espaço para implementação da gestão ambiental, uma vez que ela mostra os impactos negativos que a própria escola causa ao meio ambiente e, ao mesmo tempo, contribui na projeção de caminhos necessários para reduzir tais impactos (ações de educação ambiental).

\subsection{Oficina de artes}

A atividade Oficina de Artes foi custeada com parte do dinheiro arrecadado com a venda das latinhas de alumínio. Essa ação mostra o compromisso que o projeto Desafio Ambiental teve para os alunos, servidores e comunidade local, uma vez que os produtos adquiridos nas ações de EA eram em benefício da própria comunidade acadêmica. As garrafas de vidro utilizadas na Oficina de Artes foram coletadas pela equipe organizadora do projeto em estabelecimentos externos ou junto à comunidade local. Após a customização, as garrafas foram doadas para os próprios participantes da oficina de forma a divulgar o trabalho artístico produzido com materiais de baixo custo. Nascimento (2020), em sua pesquisa, sinalizou que ao levar alunos do curso técnico integrado ao meio ambiente ( $3^{\circ} \mathrm{Ano}$ ) para construir um espaço verde na escola (pintura de vasos feitos de PET, por exemplo), para além da sala de aula, identificou uma transformação visível do ambiente escolar, bem como na formação do aluno pautada na reflexão-ação-reflexão.

Durante a explanação técnica pela artesã convidada para a atividade, esta apontou a importância do reaproveitamento de resíduos sólidos gerados pela população (Figura 6). Para tanto, ela mostrou que seriam usados materiais como garrafas PET cortadas ao meio para acondicionar água no intuito de fazer a limpeza dos pincéis, retalhos de tecido para secar os pincéis, pratos de papelão como suporte para as tintas, jornais velhos e materiais escolares usados (lápis, borracha). Nessa mesma linha de pensamento, os benefícios ambientais, sociais e econômicos da produção de sacolas mediante o aproveitamento de banners foram mostrados por Elton e Barata (2020). Por ser um material de alta durabilidade, artesãs vinculadas ao Centro de Referência da Assistência Social (CRAS) produziram e utilizaram sacolas retornáveis, mostrando que o impacto ambiental dessa matéria-prima é reduzido quando reutilizado.

Figura 6 - A) Artesã explicando a técnica de pintura em garrafa de vidro e B) e C) Garrafas de vidro customizadas ao final da atividade

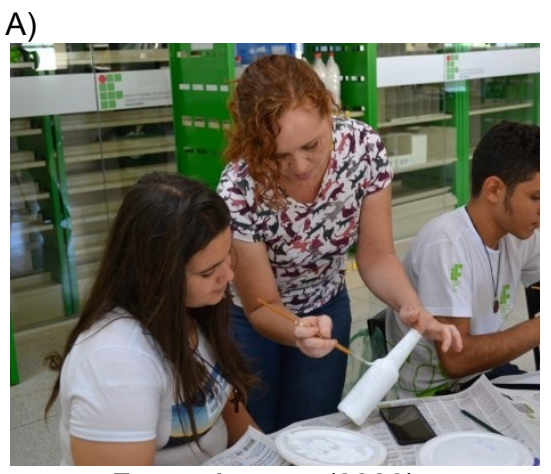

Fonte: Autores (2020)

Por fim, com a finalização da oficina, cada aluno inscrito e presente na atividade garantiu um ponto para a equipe à qual pertencia. Compareceram na atividade dois alunos do curso técnico integrado em eletrotécnica ( 2 pontos), quatro alunos do curso técnico integrado em química (4 pontos), um aluno do curso de engenharia de controle e automação (1 ponto) e uma servidora (jornalista). Mais uma vez percebese pelo público participante que os alunos do ensino médio participaram em peso na atividade.
C)

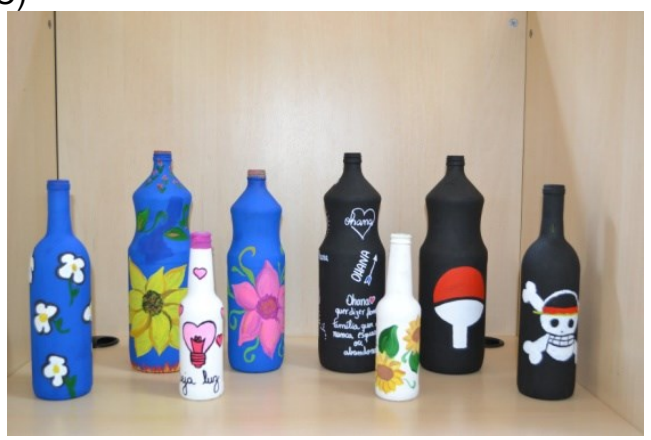

\subsection{Caça ao tesouro: explorando o acervo da biblioteca}

A princípio, o bibliotecário lotado na Biblioteca Maria Gabriela Pacheco Pardey realizou uma breve apresentação para os participantes da atividade. Durante sua explanação, o bibliotecário fez menção a assuntos como classificação de livros, tour no acervo bibliográfico do IFG/Câmpus Itumbiara, informações básicas constantes na lombada, capa e contracapa dos livros e disposição deles nas prateleiras. Muitos 
alunos ficaram surpresos ao saberem como se originam as informações da lombada do livro. Esse trabalho minucioso de catalogação, organização, gerenciamento, uso de softwares e outros, segundo Shitsuka et al. (2019), faz parte das várias habilidades e competências do bibliotecário que garantem a qualidade do gerenciamento de um número grande de obras.

Durante a realização de cada rodada do Caça ao tesouro foi possível observar que os alunos estavam muito engajados em desvendar rapidamente o enigma (sequência de caracteres) do criptex. Ademais, observouse que um dos grupos participantes estabeleceu uma divisão dos enigmas presentes no mapa entre os membros do próprio grupo, o que contribuiu para a resolução mais rápida da sequência de caracteres. Essa estratégia adotada por esse grupo (equipe B) Ihe garantiu uma pontuação de 7 pontos contra 2 pontos adquiridos pela equipe A. Observa-se as equipes desvendando os enigmas do criptex na Figura 7.

Figura 7 - A) e B) Alunos tentando desvendar a combinação do criptex, C) alunos no acervo

A)

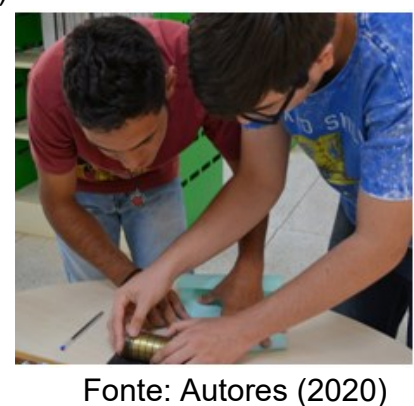

B)

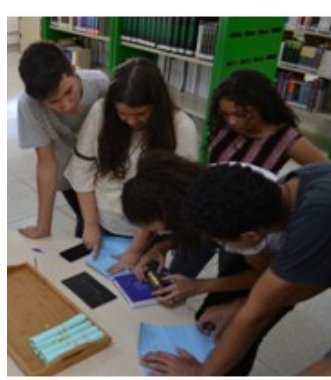

C)

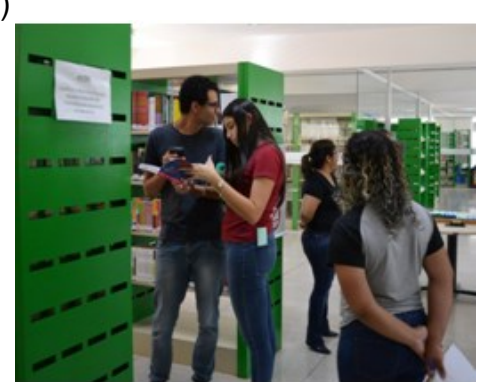

Como mencionado na metodologia, em cada rodada o grupo vencedor tinha o direito de escolher uma chave de armário e descobrir, portanto, o prêmio adquirido (Figura 8). Os prêmios eram livros doados pelos próprios organizadores do projeto (livros usados, mas com alto nível de qualidade) e Kit ambiental que foi reutilizado de outro evento da biblioteca (Semana do meio ambiente). Esse reaproveitamento de materiais educativos foi pensado justamente para integrar à proposta de sustentabilidade levantada ao longo do Desafio Ambiental, mas também para ressaltar que a educação de qualidade só é possível mediante o incentivo da educação, leitura e da informação (VIANA; CAVALCANTE; PIMENTA, 2019).

Figura 8 - A) Criptex e mapas utilizados na atividade, B) Livro doado como prêmio na atividade e C) Kit ambiental reaproveitado do evento da Semana do Meio Ambiente do IFG

A)

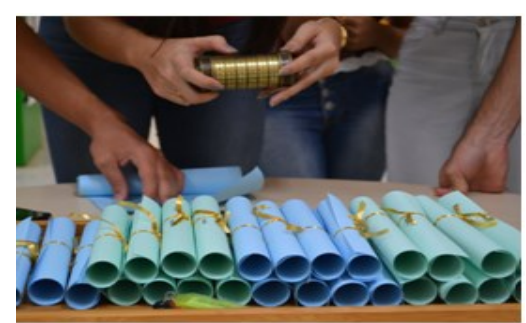

Fonte: Autores (2020)

\subsection{Encerramento do Desafio Ambiental}

No intuito de dar transparência ao Desafio Ambiental, os organizadores do projeto fizeram uma breve apresentação por slides (Figura 9A) apontando algumas informações como objetivos do desafio,
B)

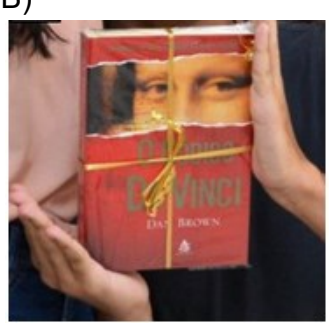

C)

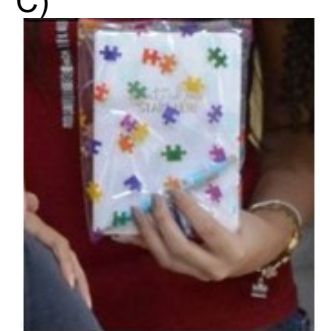

divisão das equipes, pontuação do Caça ao Tesouro por rodada e total, pontuação da Oficina de Artes por participação, total de participantes da campanha Lixo por Livro (alunos, servidores e funcionária terceirizada), total de latinhas arrecadadas, livros doados e dinheiro arrecadado na venda 
das latas, participantes que mais doaram latinhas, incluindo premiação do maior doador, quantidade de latinhas arrecadadas por equipe, ranking de pontuação final das equipes $e$, anúncio da equipe vencedora. Os resultados obtidos no Desafio (Figura 9B) justificam a vitória e participação expressiva do ensino médio, uma vez que estes alunos são os maiores frequentadores e leitores da Biblioteca Maria Gabriela Pacheco Pardey segundo levantamentos realizados internamente pelo setor. Por outro lado, a não participação dos cursos superiores provavelmente esteja relacionado ao tempo reduzido que estes alunos têm quando vão para a instituição de ensino.

Figura 9 - A) Apresentação dos resultados aos participantes e B) Resultado do Desafio Ambiental A)

B)
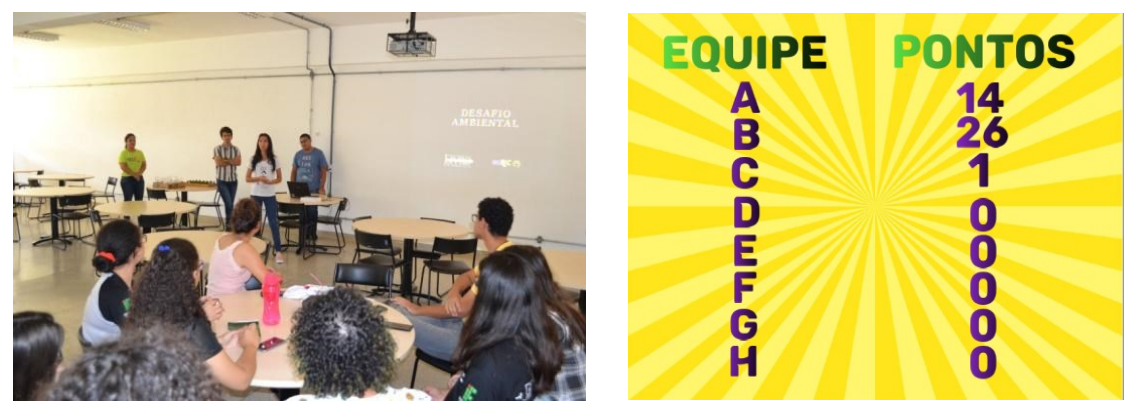

Fonte: Autores (2020)

Para a premiação do desafio foram elaborados mini troféus com o símbolo do IFG, kit de doces e livros novos para o maior doador de latinhas (Figura 10). Os prêmios foram pensados levando-se em consideração a sustentabilidade e o incentivo à leitura. Semelhante a essa ideia de premiação, Távora (2012) propôs uma gincana de arrecadação de materiais recicláveis com todos os alunos de uma escola no intuito de premiar a turma que levasse o maior peso de materiais recicláveis, sendo premiada com uma viagem para a praia da Baleia, que é uma praia da região distante a $55 \mathrm{~km}$ do centro urbano de Itapipoca. Ações de EA dentro da escola despertam no educando a necessidade de se buscar soluções aos problemas ambientais presentes no cotidiano, assim como promove um elo entre a sociedade e a natureza (BARROS; PINHEIRO, 2017). Ademais, é necessário mostrar aos alunos que apesar de serem geradores de resíduos, mesmo não sendo mais seu proprietário, ainda continuam ambientalmente responsável por ele. Portanto, dar o destino correto do resíduo (coleta seletiva), reutilizar ou reaproveitar são pequenas ações que minimizem os impactos destes no meio ambiente (BONJARDIM; PEREIRA; GUARDABASSIO, 2018). Enfim, o acompanhamento de ações de EA nas instituições de ensino é elementar para verificar as resistências e dificuldades presentes ao longo do processo e, assim, favorecer a formação ambiental de toda comunidade acadêmica (FLAMINI; PRINTES, 2019).

Figura 10 - A) Mini troféu do IFG, B) Kit de doces e C) Livros literários novos entregues à maior doadora de latinhas

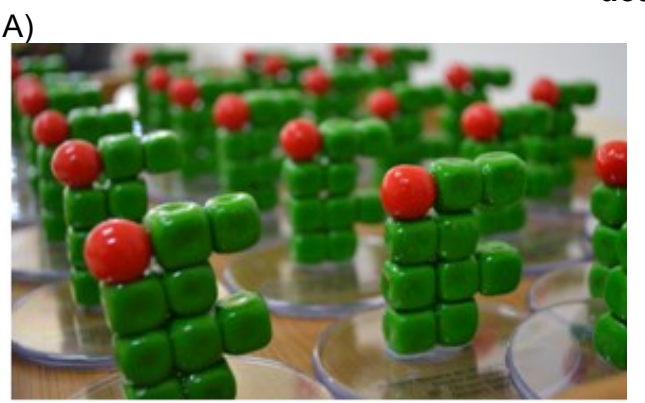

B)

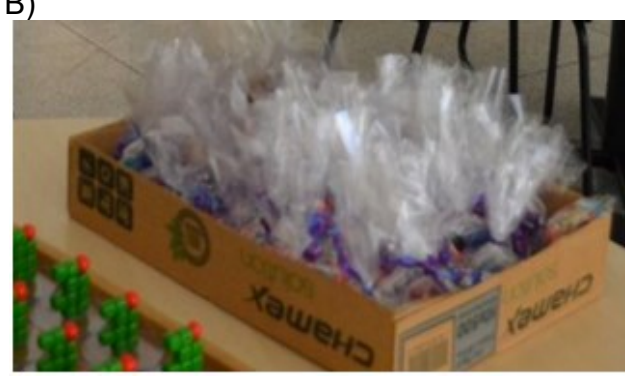

C)

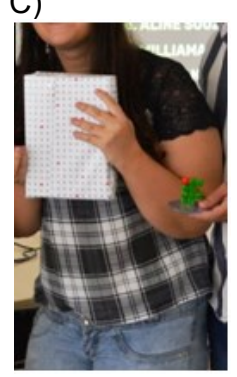

Fonte: Autores (2020) 


\section{Conclusões}

Percebe-se que a Biblioteca, dentro de uma instituição de ensino pública, tem um papel educacional, social, cultural e político que vai além dos serviços tradicionais prestados por ela aos estudantes, professores, técnico-administrativos e comunidade local. Ao articular projetos de cunho ambiental com a informação e levar tais discussões para o espaço da biblioteca, poderá contribuir numa maior sensibilização desses usuários atendidos diariamente a respeito dos impactos ambientais oriundos das ações antrópicas inadequadas. A temática "resíduos sólidos" sendo ensinada pelos profissionais da biblioteca e pautada na metodologia da pesquisa-ação participante mostrou-se adequada para obtenção de reflexões acerca da importância do papel ativo do sujeito em ações de educação ambiental, favorecendo uma maior sensibilização em prol do desenvolvimento sustentável.

Apesar de alguns participantes sinalizarem que já praticavam a separação das latas de alumínio em casa e da existência de coletores seletivos na comunidade acadêmica, ficou evidente pelos autores que as ações intensificaram ainda mais a consciência ambiental com relação à importância da gestão correta dos resíduos sólidos, principalmente na comunidade acadêmica. Por outro lado, não foi possível perceber mudanças significativas na comunidade local em função da inexistência de participantes na campanha de arrecadação. No entanto, alunos relataram que pediram ajuda de amigos, colegas de trabalho e familiares para coleta de latinhas ao longo das ruas da cidade de Itumbiara-GO, contribuindo, assim, indiretamente para a gestão adequada dos resíduos e vivendo de perto o impacto desses resíduos no ambiente. $\mathrm{Na}$ oficina de produção de garrafas decorativas foi possível observar que os alunos sentiram a atividade como sendo muito prazerosa e relaxante, além de aprenderem ações de sustentabilidade que podem ser reproduzidas em casa (aproveitamento de materiais caseiros). Já a Caça ao tesouro foi a atividade que mais estimulou os alunos, sem contar que muitos alunos alegaram já conhecer a distribuição de livros no acervo, assim como os métodos de classificação.

Enfim, ações de EA pautadas em métodos didáticos motivadores não devem ser utilizados isoladamente na sala de aula, mas sim como uma ação contínua e integrada, de forma que os profissionais de biblioteconomia e correlatos, comunidade acadêmica e local possam estabelecer um trabalho contínuo sobre destinação correta dos resíduos sólidos, assim como propor ações educativas de reuso desses materiais.

\title{
5 Environmental challenge: report of an experience about solid waste in library
}

\begin{abstract}
Solid waste that are improperly disposed of by the population, have significantly interfered with environmental quality. In consequence, studies have been developed to reduce the deleterious effects caused by these materials. In this sense, the aim of this work was to promote environmental awareness among users and the community of the Maria Gabriela Pacheco Pardey Library in relation to the benefits arising from the reuse of solid waste discarded through an Environmental Challenge, integrating the environment and library science. The Environmental Challenge project was carried out during the National Book and Library Week of the Federal Institute of Education, Science and Technology of Goiás (IFG) - Campus Itumbiara and was attended by 124 students, 12 public servants and 1 outsourced employee. The activities, developed and based on participatory action research, were: Trash for Book, Scavenger Hunt: Exploring the Library's Collection and Arts Workshop. At the end of the challenge, 8,631 aluminum cans were collected and 150 books were donated. The results of this differentiated experience provided a reflection about library's educational role, the importance of environmental education actions integrated with the solid waste theme and, mainly, the exchange of knowledge between those involved in the project.
\end{abstract}

Keywords: Environmental education; Sustainability; Environment; Solid waste.

\section{Referências}

ABRELPE. Associação Brasileira de Empresas de Limpeza Pública e Resíduos Especiais. Panorama dos Resíduos Sólidos no Brasil 2018/2019. Disponível em: http://abrelpe.org.br/panorama/. Acesso em: 09 jun. 2020. 
ABU HAJAR, H. A.; TWEISSI, A.; ABU HAJAR, Y. A.; AL-WESHAH, R.; SHATANAWI, K. M.; IMAM, R.; MURAD, Y. Z.; ABU HAJER, M. A. Assessment of the municipal solid waste management sector development in Jordan towards green growth by sustainability window analysis. Journal of Cleaner Production, $\quad 128: 120539, \quad 2020$. doi:10.1016/j.jclepro.2020.120539.

ALMEIDA, Jailson de Arruda. Gestão de resíduos sólidos em instituições de ensino: experiências internacionais, nacionais e no município de Belo Jardim/PE. Revista Gestão \& Sustentabilidade Ambiental, v. 7, n. 1, p. 467-485, 2018.

ATHAYDE JUNIOR, G. B.; BESERRA, L. B. de S.; FAGUNDES, G. de S. Sobre a geração de resíduos sólidos domiciliares em bairros de classe média e alta de João Pessoa. Revista de estudos ambientais, v. 9, n. 2, p. 73-88, 2007.

BARROS, H. C.; PINHEIRO, J. de Q. Mudanças climáticas globais e o cuidado ambiental na percepção de adolescentes: uma aproximação possível. Desenvolv. Meio Ambiente, v. 40, p. 189-206, abr. 2017.

BITENCOURT, D. V.; ALMEIDA, R. N. de; PEDROTTI, A.; SANTOS, L. C. P. A problemática dos resíduos sólidos urbanos. Interfaces Científicas - Saúde E Ambiente, v. 2, n. 1, p. 2536, 2013. https://doi.org/10.17564/23163798.2013v2n1p25-36.

BONJARDIM, E. C.; PEREIRA, R. da S.; GUARDABASSIO, E. V. Análise bibliométrica das publicações em quatro eventos científicos sobre gestão de resíduos sólidos urbanos a partir da Política Nacional de resíduos Sólidos - Lei $n^{\circ}$ 12.305/2010. Desenvolv. Meio Ambiente, v. 46, p. 313-333, ago. 2018.

BRASIL. Lei 12.305 de 02 de agosto de 2010. Política Nacional de Resíduos Sólidos. Institui a Política Nacional de Resíduos Sólidos. Brasília-DF, $2010 . \quad$ Disponível em: http://www.planalto.gov.br/ccivil 03/ ato20072010/2010/lei//12305.htm. Acesso em: 08 jun. 2020.

BRASIL. Constituição (1988). Constituição da República Federativa do Brasil. Diário Oficial da União, Poder Legislativo, Brasília, DF, 5 out. 1988. Seção 1, p. 1.

BRASIL. Lei no 10.406, de 10 de janeiro de 2002. Institui o Código Civil. Diário Oficial da União, Poder Legislativo, Brasília, DF, 11 jan. 2002. Seção 1, p.1

CARDOSO, N. B. A contribuição do bibliotecário para a educação ambiental. Perspectivas em Ciência da Informação, v. 15, n. 2, p. 140-162, mai./ago. 2010.
CEMBRANEL, A. S.; FRANCISCHETT, M. N.; RODRIGUES, C. R. Educação ambiental com estudantes e famílias na gestão dos resíduos sólidos urbanos. Revbea, v. 14, n. 1, p. 171-185, 2019.

ELTON, D.; BARATA, J. T. S. S. A. Arte criativa sustentável: reaproveitamento de banners em oficina de costura. In: Anais do Salão Internacional de Ensino, Pesquisa e Extensão, v. 11, n. 2, 30 mar. 2020.

EVERTON, V. G.; VIESBA, G. L.; ROSALEN, M. Educação Ambiental para a Sustentabilidade: Formação Continuada em Foco. HUMANIDADES \& TECNOLOGIA EM REVISTA (FINOM). Ano XIII, v. 16, n. 1, p. 10-24, Jan/Dez 2019.

FAGUNDES, A. B.; RUTKOWSKI, A. K.; MIKUS, B. C.; PEREIRA, D.; BEUREN, F. H. Garrafas PET: problemática e aplicações pós-consumo. Revista Produção Industrial \& Serviços, v. 2, n. 2, p. 9098, 2019.

FLAMINI, S. H.; PRINTES, L. B. Percepção socioambiental: o Projeto Canecas e o Programa de Coleta Seletiva Solidária da Universidade Federal de São Carlos, São Paulo, Brasil. Pesquisa em Educação Ambiental, v. 14, n. 1, p. 111-131, 2019.2 DOI: http://dx.doi.org/10.18675/2177-

580X.vol14.n1.p111-131.

FRIEDE, R. R.; REIS, D. de S.; AVELAR, K. E. S.; MIRANDA, M. G. de. Coleta seletiva e Educação Ambiental: reciclar valores e reduzir o lixo. Educação \& Formação, v. 04, n. 11, p. 117 - 141, mai./ago. 2019.

GIL, A. C. Como elaborar projetos de pesquisa. 4. ed. São Paulo: Atlas, 2002.

JACOBI, P. R.; GRANDISOLI, E. Água e sustentabilidade: desafios, perspectivas e soluções. São Paulo: IEE-USP e Reconectta, $1^{\text {a }}$ Edição, 2017.

JULIATTO, D. L.; CALVO, M. J.; CARDOSO, T. E. Gestão integrada de resíduos sólidos para instituições públicas de ensino superior. Revista Gestão Universitária na América Latina, Florianópolis, v. 4, n. 3, p.170-193, set/dez. 2011.

MARCONI, M. A.; LAKATOS, E. M. Fundamentos de metodologia científica. 5. ed. São Paulo: Atlas, 2003

MEDEIROS, M. F.; SILVA, T. F. da; ARAÚJO, C. R. L. de. Leitura em todos os sentidos: um projeto extensionista de incentivo à leitura. In: Anais do Salão Internacional de Ensino, Pesquisa e Extensão, v. 11, n. 3, fev./2019.

MEDEIROS, M. S.; PACHECO, I. da S.; PADILHA, E. T.; GIROTTO, L. G.; CABRAL, A. C. e S.; AMARAL, F. A. do; SILVEIRA, H. E. da; 
CANOBRE, S. C. Estratégias pedagógicas fundamentadas na pesquisa-ação participativa para a sensibilização de educandos de escolas do campo de Uberlândia (MG) sobre o tema "água". Pesquisa em Educação Ambiental, v. 12, n. 2, p.24-39, 2017

http://dx.doi.org/10.18675/2177-

580X.vol12.n2.p24-39.

MELO, N. H. P. L. de; PESSOA, J. C. M. Projeto: "Lixo por Livro". In: Seminário promovido pela Escola de Biblioteconomia da Universidade Federal de Minas Gerais e Associação dos Bibliotecários de Minas Gerais, 1998, Belo Horizonte.

MOREIRA, J. A.; DUARTE, A. B. S. Práticas educativas bibliotecárias de formação de leitores: uma análise inicial de projetos da Rede Municipal de Educação de Belo Horizonte a partir de modelos de trabalho colaborativo entre bibliotecários e professores. In: XXV Congresso Brasileiro de Biblioteconomia, Documento e Ciência da Informação - Florianópolis, SC, Brasil, 07 a 10 de julho de 2013.

NASCIMENTO, W. A. Educação ambiental e ressignificação do espaço escolar: estudo de caso em uma escola de ensino técnico do estado do Pará. Revista Prática Docente, v. 5, n. 1, p. 156171, jan./abr. 2020.

PEREIRA, E. V. Resíduos Sólidos. Edição 1. São Paulo: Editora Senac, 2019. 311p.

POZZETTI, V. C.; CALDAS, J. N. O descarte de resíduos sólidos no âmago da sustentabilidade. Revista de Direito Econômico e Socioambiental, Curitiba, v. 10, n. 1, p. 183-205, jan./abr. 2019.2 DOI: 10.7213/rev.dir.econ.soc.v10i1.24021.

SEREIA, D. O.; CARVALHO, F.; COSTA, J. S.; BARROS, I. T.; BORTOLI, M. M. Sistemas de gestão ambiental: a reciclagem como um instrumento para a sensibilização no meio ambiente escolar. Revista de estudos ambientais, v. 15, n. 1, p. 60-74, 2013.

SHITSUKA, D. M.; SHITSUKA, R.; PEREIRA, A. S.; BRITO, M. L. de A.; BOGHI, C. Imagens dos bibliotecários desveladas por meio de Charges. Res. Soc. Dev., v. 8, n. 7, p. 1-22, 2019. DOI: http://dx.doi.org/10.33448/rsd-v8i7.1098.

SILVA, V. R. M. J.; SILVA, A. L. J.; CARDOSO, S. P. Guia Prático em Educação Ambiental: Sensibilizando de Forma Crítica, Transversal e Lúdica. Revista de Educação, Ciências e Matemática, v. 9, n. 2, maio/ago 2019. ISSN 22382380.

SILVA, J. J. R. da; NEVES, F. A. Educação ambiental na escola: um espaço de colaboração. In: CAMPELO-JUNIOR, M. V.; SIQUEIRA, J. F. R. A educação ambiental nas escolas estaduais de Mato Grosso do Sul. Campo Grande - MS: SED, 2020. 210 p. ISBN 978-6588366-02-8.

SPINELLI, M. V. P.; CARVALHO, R. M. C. M de O.; SILVA, H. P. da; BRANDÃO, S. S. F.; FRUTUOSO, M. N. M. de A. Estudo sustentável da capacidade de carga antrópica e a sua influência no ponto de equilíbrio da resiliência ambiental. Revista Brasileira de Geografia Física, v. 09, n. 01, p. 185-199, 2016.

TÁVORA, M. A. Práticas e reflexões sobre a educação ambiental na escola pública: a gestão de resíduos sólidos na E. E. F. M. Cel. Murilo Serpa em Itapipoca-CE. Revbea, v. 7, p. 37-43, 2012.

TOZONI-REIS, M. F. C. Pesquisa-ação em educação ambiental. Pesquisa em Educação Ambiental, São Paulo, v. 3, n. 1, p. 155-169, 2008.

VIANA, G. de M.; CAVALCANTE, F. de O. F.; PIMENTA, J. S. Caminhos da leitura: a experiência da "tenda da leitura" no Instituto Federal de Rondônia Campus Cacoal. Revista Fontes Documentais, v. 2, n. 3, p. 59-74, set./dez. 2019.

\section{Agradecimentos}

Agradecemos ao IFG - Câmpus Itumbiara e aos alunos, servidores e comunidade externa que participaram do projeto. 